\title{
Functional involvement of src and focal adhesion kinase in a CD99 splice variant-induced motility of human breast cancer cells
}

\author{
Hyuk-Joon Lee ${ }^{1}$, Eunsook Kim ${ }^{1}$, \\ Bokeun Jee', Jang-Hee Hahn², \\ Kyuhyoung $\mathrm{Han}^{3}$, Kyeong Cheon Jung ${ }^{4}$, \\ Seong Hoe Park ${ }^{5}$ and Hansoo Lee ${ }^{1,6}$ \\ ${ }^{1}$ Vascular System Research Center, Division of Life Sciences, Col- \\ lege of Natural Sciences, Kangwon National University, Chunchon \\ 200-701 \\ ${ }^{2}$ Department of Anatomy, College of Medicine, \\ ${ }^{3}$ Department of Genetic Engineering, College of Natural Sci- \\ ences, Hallym University, Chunchon 200-141, \\ ${ }^{4}$ Department of Pathology, College of Medicine, \\ ${ }^{5}$ Department of Pathology, College of Medicine, Seoul National Uni- \\ versity, Seoul 110-799, South Korea \\ ${ }^{6}$ Corresponding author:Tel, +82-33-250-8530; \\ Fax, +82-33-251-3990; E-mail, hslee@ kangwon.ac.kr
}

Accepted 25 May 2002

Abbreviations: FAK, focal adhesion kinase; ERK, extracellular signal-regulated kinase; JNK, c-jun N-terminal kinase; mAb, monoclonal antibody

\begin{abstract}
Earlier report showed that expression of a splice variant of CD99 transmembrane protein increases invasive ability of human breast cancer cells. Cell motility was also significantly enhanced by the CD99 splice variant expression. In an effort to identify the cellular components that mediate a signal transduction pathway tiggered by the CD99 splice variant, known signal path inhibitors were examined for their effects on the motility of the CD99 splice varianttransfected MDA-MB-231 breast cancer cells. Phenylarsine oxide, an inhibitor of phosphatase specific for focal adhesion kinase, and PP1, an inhibitor of src kinase family, significantly suppressed motility of the cells. Among different types of src transfectant clones generated, kinase-negative mutant src transfectant cells were $\mathbf{8 0} \%$ less motile than the mock cells transfected with an empty-vector, while v-src and $c$-src transfectants exhibited cell motility levels at or slightly above the mock transfectant. These results suggest that src and focal adhesion kinase mediate the intracellular signaling pathway of a CD99 splice variant for the induction of motility of human
\end{abstract}

\author{
breast cancer cells.
}

Keywords: breast cancer, CD99, focal adhesion kinase, motility, splice variant, src.

\section{Introduction}

CD99 is a transmembrane glycoprotein with a molecular mass of $32 \mathrm{kDa}$ encoded by the MIC2 gene (Levy et al., 1979). The CD99 protein has been implicated in various cellular processes of hematopoietic cells, including homophilic cell adhesion, apoptosis, vesicular protein transport, and thymocyte differentiation (Bernard et al., 1995; 1997; Choi et al., 1998; Sohn et al., 2001). Although the ligand(s) for CD99 is yet to be identified, cross-linking of CD99 molecules with an anti-CD99 monoclonal antibody was shown to induce homotypic aggregation of lymphocytes, along with up-regulation of LFA-1 $\left(\alpha_{\llcorner} \beta_{2}\right.$ integrin) expression, suggesting that signal transduction via CD99 modulates cell adhesion of lymphocytes by regulating the expression level of cell adhesion molecules (Bernard et al., 1995; Hahn et al., 1997). It was recently reported that the induction of homotypic aggregation of Jurkat $T$ cells by CD99 activation is mediated by protein kinases including MAP kinases, protein tyrosine kinases, and protein kinase C (Hahn et al., 2000; Kasinrerk et al., 2000).

The CD99 gene encodes two distinct proteins, which are produced by alternative splicing of the CD99 gene transcript (Hahn et al., 1997). Interestingly, the minor, splicing variant form of CD99 inhibited homotypic adhesion of B cells, while activation of the major CD99 form promoted the adhesion process, indicating that the CD99 gene produces two distinct proteins with opposite functions in adhesion process of lymphocytes. Since the two forms of CD99 were shown to be differentially expressed in many human cells and highly conserved in monkey, it was suggested that the two forms of CD99 function in vivo in both positive and negative regulation of homophilic cell adhesion of lymphocytes during differentiation and immune responses (Hahn et al., 1997).

CD99 is broadly distributed on many cell types, and strongly expressed on human cortical thymocytes, Ewings sarcoma cells and peripheral primitive neuroectodermal tumors (Kovar et al., 1990; Ambros et al., 1991). Especially, the alternatively spliced isoforms of CD99 transcripts are differentially expressed in a cell typespecific manner among hematopoietic cells (Hahn et 
al., 1997). In a previous study of the CD99 expression in human breast cancer cell lines, a highly metastatic breast adenocarcinoma cell line, MDA-MB-435 was found to express both the major form and splice variant of CD99, while a non-invasive breast adenocarcinoma cell line, MCF-7 expresses only the major CD99 form. Such results suggest that expression of the CD99 splice variant may be differentially regulated during development and/or progression of human breast cancer. Interestingly, transfection of an invasive breast adenocarcinoma cell line, MDA-MB-231 lacking both the CD99 types with an expression construct of the CD99 splice variant, significantly enhances in vitro invasiveness and inhibition of homophilic cell adhesion (Kim et al., 2000). Several studies have demonstrated the CD99 molecule as a signal transducer. Whether the CD99 variant also functions either as an inhibitor of CD99 induced cell signal path and/or an independent signal transducer to induce such cellular activities as invasion and homotypic cell adhesion is not known. In the present study, we investigated signal transduction pathway(s) downstream of the CD99 splice variant in breast cancer cells.

\section{Materials and Methods}

\section{Cell culture}

MDA-MB-231 human breast adenocarcinoma cell line was cultured in DMEM supplemented with $10 \%$ fetal bovine serum (FBS), 100 units $/ \mathrm{ml}$ penicillin, and $100 \mu \mathrm{g} / \mathrm{ml}$ streptomycin (all from Gibco-BRL, Grand Island, NY, USA). For cultures of the CD99 splice variant-transfected MDA-MB-231 cells, G418 was added to the complete DMEM at a concentration of $0.8 \mathrm{mg} / \mathrm{ml}$. Cell cultures were main-tained and incubated in $5 \% \mathrm{CO}_{2}$ at $37^{\circ} \mathrm{C}$.

\section{Migration assay}

Cell motility was measured by wound migration assay as described previously (Shin et al., 2001). Briefly, the CD99 splice variant transfectant cells $\left(5 \times 10^{5}\right)$ in $2 \mathrm{ml}$ of culture medium containing $10 \%$ FBS and $0.8 \mathrm{mg} / \mathrm{ml}$ G418 were seeded in a well of 24-well culture plate. When the cells grew up to confluent state, a wound was made in the confluent monolayer with a plastic micropipette tip having large orifice. The medium and debris were aspirated away and replaced by $2 \mathrm{ml}$ of fresh medium. For the evaluation, photographs of wounded area were taken just after making a wound and every $24 \mathrm{~h}$ after incubation, respectively. The extent of migration was quantified by measuring the migration distance of each group of cells.

\section{Transfection experiments}

The cDNA expression construct encoding c-src, v-src or dominant-negative mutant src lacking kinase activity was cotransfected with a pTK/Hyg (Invitrogen, Carlsbad, CA, USA) into the CD99 splice variant-transfected MDA-MB231 breast cancer cells by using lipofectAMINE (Gibco$\mathrm{BRL}$ ) according to the manufacturer's instructions. PTK/ $H y g$ vector only was also transfected as a control. Src transfectants were selected in DMEM containing $10 \%$ FBS, $0.8 \mathrm{mg} / \mathrm{ml} \mathrm{G} 418$ and $0.3 \mathrm{mg} / \mathrm{ml}$ hygromycin (Gibco$\mathrm{BRL}$ ). Resistant clones were cloned by ring isolation after 4 weeks of selection.

\section{Selection of src overexpressers}

Lysates of each stable transfectant clone resistant to both neomycin and hygromycin were prepared for Western blot analysis as described (Lee et al., 1993; Ha-Lee et al., 2000). Lysates containing equal amounts of protein were resolved on $8 \%$ SDS-PAGE, the proteins were transferred to Immobilon-P (Millipore, Bedford, MA, USA) and the membranes were incubated with an anti-src monoclonal antibody (Oncogene, Cambridge, MA, USA) followed by rabbit anti-mouse IgG-peroxidase conjugate (PharMingen, San Diego, CA, USA). The src antibody-anti-mosue IgG complex was detected by using ECL reagent (Amersham, Piscataway, NJ, USA).

\section{Results}

\section{A CD99 splice variant promotes motility of breast cancer cells}

To investigate the functional effects of CD99 molecules on the metastatic phenotypes of cancer cells, several CD99 transfectant clones of MDA-MB-231 human breast adenocarcinoma cells lacking CD99 expression were generated. Those CD99 tranfectant clones stably overproduced either a major form (type I) or a splice variant (type II) of CD99 protein on cell surface. Among those CD99 transfectant clones, the CD99 type IItransfected clone displayed significantly increased invasiveness when compared with the control transfectant while the CD99 type I-transfected clone did not (Kim et al., 2000). Since invasiveness in vivo is closely reflect motility in vitro, the migrating ability of the CD99 transfectant clones was examined. As shown in Figure 1, the CD99 type II transfectant clone exhibited more than 3-fold higher migrating ability than the control transfectant, whereas no significant difference in cell motility was observed between the CD99 type I and control transfectant.

A FAK phosphatase inhibitor, phenylarsine oxide and a src kinase inhibitor, PP1 suppress cell motility of the CD99 type II transfectant

Both types of CD99 molecule have been shown to trigger intracellular signals leading to alterations in 
A

Control
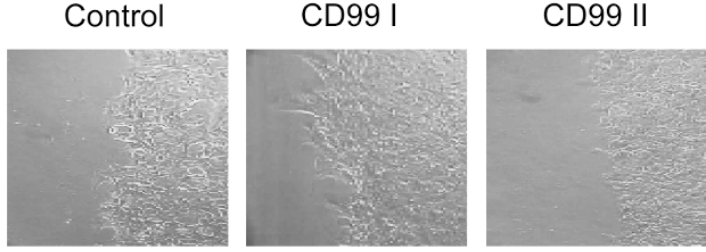

$48 \mathrm{~h}$
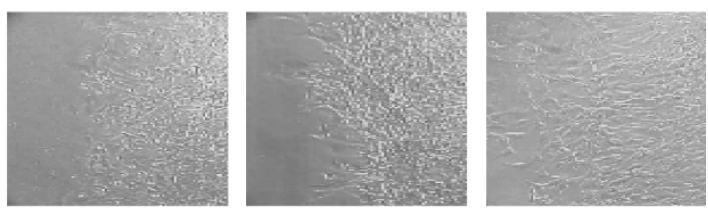

B

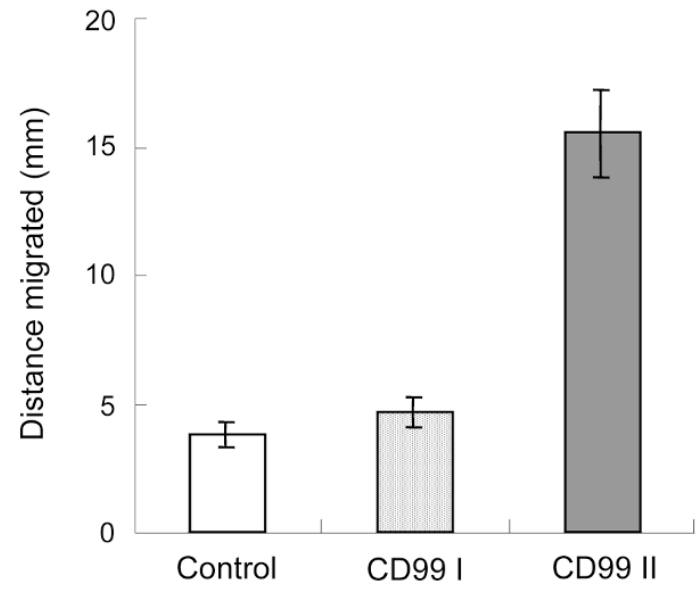

Figure 1. In vitro cell motility of the CD99 type I and type II transfectant clones. The CD99 type I- and type II-transfected MDA-MB-231 clones (5 X $10^{5}$ cells) were seeded in each well of 24-well plates. When the cells were grown to confluent state, the cell layer was wounded with a plastic micropipette tip. (A) Photographs were taken at $48 \mathrm{~h}$ after wound was made, and the migrating distance of each cell was measured for cell motility. (B) Shown in a bar graph are mean \pm SEM $(n>30)$. The difference in motility between the control and CD99 splice variant transfectant cells was statistically significant $(P<0.01$, Student's $t$-test $)$.

homotypic aggregation of various cell types. On the other hand, it would be difficult to accept that CD99 type II transfactant clones with far greater cell migrating activity would have the same cell signal path of the CD99 expressing cells. As an effort to explore signaling pathway(s) taken downstream of the CD99 type II for the induction of cell motility, we first examined migrating ability of the CD99 transfectant cells after treatment with phenylarsine oxide, an inhibitor of FAK phosphatase which plays an important role in signaling pathway of integrin-mediated cell migration. CD99 type II-induced cell motility was blocked for the most part by pretreatment with phenylarsine oxide (PAO) (Figure 2). Whereas, the intrinsic migratory capacity of MDA-MB231 cells and CD99 type I transfectants were not much affected by PAO treatment. Such inhibition on motility of the CD99 type II-expressing cells by PAO suggests that focal adhesion kinase in associated with integrin may

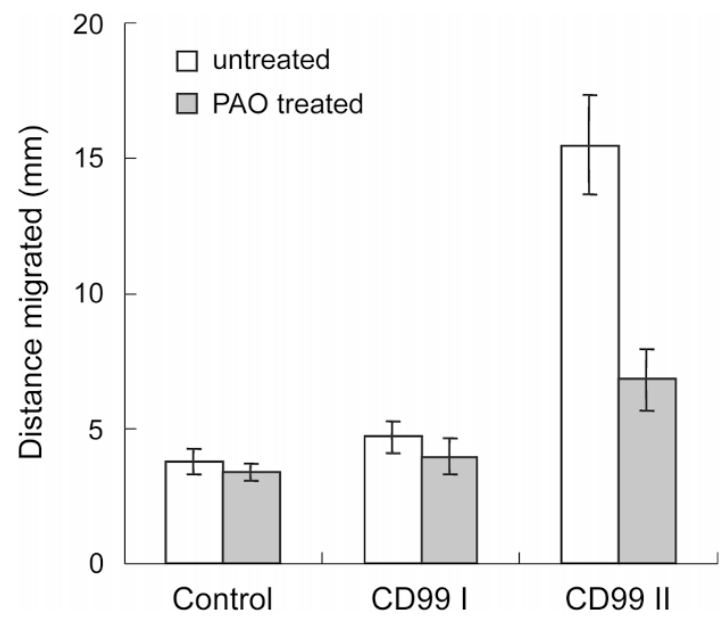

Figure 2. Cell motility of the CD99 type I and type II transfectant clones after treatment with an inhibitor of FAK phosphatase. The CD99 type I- and type II-transfected MDA-MB-231 cells were pretreated for 5 min with $5 \mu \mathrm{M}$ phenylarsine oxide (PAO), an inhibitor of FAK phosphatase, or with vehicle control (DMSO) and then assayed for cell motility as in Figure 1. The difference in motility between the untreated and PAO-treated cells in the CD99 type II transfectant was statistically significant $(\mathrm{P}<0.01$, Student's $t$ test).

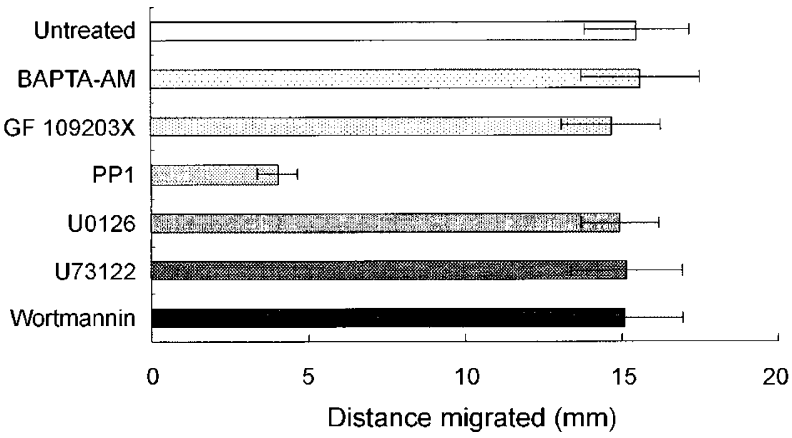

Figure 3. Cell motility of the CD99 type II transfectant in the presence of inhibitors of signal transduction mediators. The CD99 type II-transfected MDA-MB-231 cells were assayed for their migrating ability in the presence of BAPTA-AM $(7.5 \mu \mathrm{M})$, GF109203X (1 $\mu \mathrm{M})$, PP1 $(1 \mu \mathrm{M})$, U0126 $(1 \mu \mathrm{M})$, U73122 $(1 \mu \mathrm{M})$ or wortmannin $(50 \mathrm{nM})$, respectively. Data represent the mean \pm SEM of triplicate determinations. The difference in motility between the untreated and PP1-treated cells was statistically significant $(P<0.01$, Student's t-test)

modulate the motility-promoting function of CD99 type II. Cell motility of the CD99 type II transfectant was also investigated in the presence of the other inhibitors for signal transduction mediators in a several-fold higher, but not lethal, dose than a dose of $\mathrm{IC}_{50}$ : BAPTA-AM, an intracellular calcium chelator; GF109203X, a PKC inhibitor; PP1, a src kinase inhibitor; U0126, an ERK kinase (MEK) inhibitor; U73122, a phospholipase C inhibitor; wortmannin, a PI-3 kinase inhibitor. As shown in Figure 3, the inhibitor of src kinase family, PP1 significantly suppressed cell motility of the CD99 type II transfectant. The PP1-treated cells were approximately $70 \%$ less motile than the untreated cells, whereas none of the other inhibitors tested affected cell motility of the 


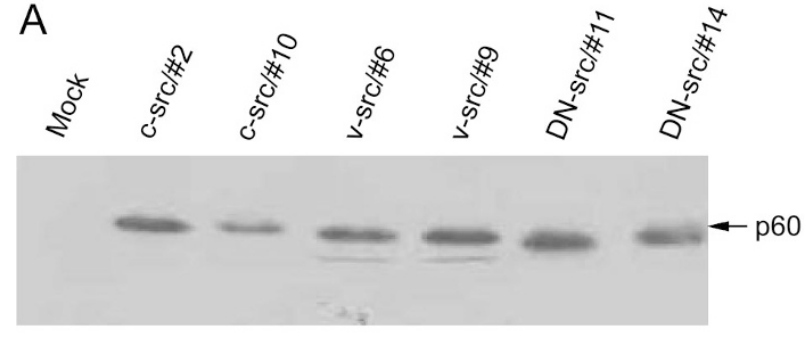

B

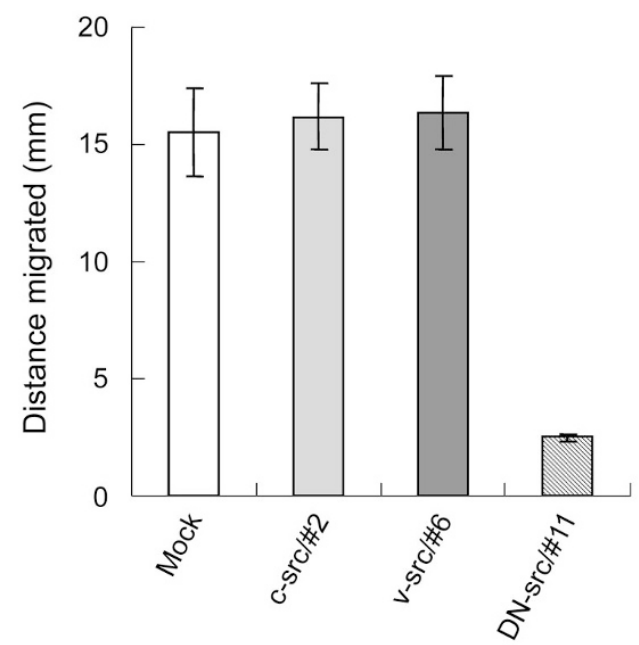

Figure 4. Cell motility of the CD99 type II transfectant after retransfection with the different types of src. (A) Src expression level of src transfectant clones. The CD99 type II-transfected MDA-MB-231 cells were retransfected with an expression construct encoding c-src, v-src or dominant-negative (DN) mutant src. Src protein level in each transfectant clone was examined by Western analysis using anti-src monoclonal antibody as described in Materials and Methods. (B) Cell motility of the src transfectant clones with CD99 type II expression. Three different types of src-transfected MDA-MB231 clones that had been pretransfected with the CD99 type II were assayed for their migrating ability as in Figure 1. Data represent the mean \pm SEM of triplicate determinations. The difference in motility between the mock and dominant-negative (DN) mutant src transfected cells was statistically significant $(P<0.01$, Student's $t$-test $)$.

CD99 type II transfectant. Because the inhibition effect of PP1 was not exerted at concentrations lower than $200 \mathrm{nM}$, it was likely that src kinase, the only kinase showing $\mathrm{IC}_{50}$ higher than $100 \mathrm{nM}$ for PP1 among src family members, is functionally involved in signaling pathway(s) of the CD99 type II for the induction of motility of breast cancer cells.

\section{Generation of different types of src-transfected stable clones with high src expression}

To verify the signal-mediating role of src kinase in the CD99 type II signaling pathway to induce cell motility, we retransfected the CD99 type II-transfected MDA-MB231 cells witd an expression construct enconding v-src, c-src or dominant-negative mutant src lacking kinase activity. Stable transfectant clones were screened for the overproduction of src protein on immunoblots using anti- src monoclonal antibody and identified several transfectant clones overexpressing src protein for each type of src construct (Figure 4A). Src protein levels in those src transfectant clones were far greater than an endogenous src protein level. And the exogenously introduced type of src kinase likely represents most of the biochemical activity exerted by src kinase in those double transfectant cells overexpressing both CD99 type II and one of the src protein types.

\section{Overexpression of mutant src protein lacking kinase activity inhibits cell motility of the CD99 type II transfectant}

Analysis of cell motility of the double transfected cells with CD99 type II and different types of src transfection is shown in Figure 4B. The overexpression of v-src and c-src protein does not significantly affect motility of the CD99 type II-transfected MDA-MB-231 cells. However, the dominant-negative mutant src-transfected clones displayed $1 / 5$ level of cell motility of the mock transfectant having endogenous src expression only, indicating that overexpression of kinase-negative src mutant protein interferes the promoting effect of CD99 type II on motility of MDA-MB-231 cells. This result strongly suggests that the CD99 type II induce motility of human breast cancer cells through src kinase-dependent pathway.

\section{Discussion}

Several studies have demonstrated the role of the major form of CD99 (type I) as a signal transducer for the induction of homotypic aggregation of immune cells, although the ligand(s) for CD99 is not yet known (Bernard et al., 1995; Hahn et al., 1997). Cross-linking of CD99 type I with an anti-CD99 monoclonal antibody (mAb) up-regulated surface LFA-1 $\alpha_{\mathrm{L}}$ integrin expression of IM-9 B and Jurkat T cells, together with induction of hymotypic cell aggregation (Hahn et al., 1997). Stimulation of CD99 type I with anti-CD99 mAb enhanced the expression of $\mathrm{T}$ cell activation markers, CD25, CD69 and CD40L on anti-CD3-activating $T$ cells, along with elevation of intracellular $\mathrm{Ca}^{2+}$ and the tyrosine phosphorylation of cellular proteins (Waclavicek et al., 1998; Wingett et al., 1999). Induction of Jurkat homotypic aggregation by anti-CD99 mAb was blocked by the protein kinase $\mathrm{C}$ inhibitor, sphingosine and the protein tyrosine kinase inhibitor, genistein (Kasinrerk et al., 2000). Treatment of Jurkat cells with anti-CD99 mAb led to differential activation of three mitogen-activated protein kinase (MAPK) members, ERK, JNK and p38 MAPK (Hahn et al., 2000). The signal-transducing role of CD99 type I for the induction of homotypic cell aggregation was not observed only in hematopoitic 
cells, but also in breast cancer cells of epithelial origin; that is, cross-linking of CD99 type I with anti-CD99 mAb induced the homophilic cell adhesion of MDA-MB-231 human breast cancer cells (Kim et al., 2000). On the contrary, we also found that activation of a CD99 splice variant (type II) with anti-CD99 mAb inhibits homotypic aggregation of the CD99 type II-transfected MDA-MB231 cells. Since the sole activation of CD99 type II was able to suppress the homotypic aggregation of MDAMB-231 breast cancer cells devoid of endogenous CD99 type I expression, the CD99 splice variant might be able to trigger its own signal transduction pathway, instead of simply interfering a signaling pathway of the major CD99 form.

We have previously found that expression of the CD99 spice variant increases invasive ability of MDAMB-231 breast cancer cells (Kim et al., 2000). When the CD99 type II transfectant cells were assayed for cell motility, the expression of the CD99 type II obviously increased the migrating ability of MDA-MB-231 cells (Figure 1). Since an alteration in physiological constraints that enable typically non-motile epithelial cells to migrate is a hallmark of cancer invasion and metastasis, the increase in invasiveness of breast cancer cells by the CD99 type II expression seems to be mostly due to the motility-promoting function of CD99 type II. To reveal the role of CD99 type II as a signal transducer, we have explored signal transduction pathway(s) taken downstream of the CD99 type II for the induction of motility of MDA-MB-231 cells. The data in the present study show that a FAK phosphatase inhibitor, phehylarsine oxide and a src kinase inhibitor, PP1 significantly blocked cell motility induced by the CD99 type II expression while inhibitors of other major signaling mediators did not (Figures 2 and 3). We also found that overexpression of src mutant lacking kinase activity suppresses the CD99 type II-induced cell motility to a great extent (Figure 4). It thus appears that src kinase indeed mediates the functional role of CD99 splice variant in the regulation of motility of human breast cancer cells, along with focal adhesion kinase.

Cell migration is a muti-step process that requires repeated adhesion to and detachment from extracellular matrix $(E C M)$. These events are largely mediated by integrins, which upon engagement with components of the ECM reorganize to form adhesion complexes termed focal adhesion complexes. The integrin clustering results in increased phosphorylation of a protein tyrosine kinase localized at the focal adhesion complexes, focal adhesion kinase (FAK) (Guan and Shalloway, 1992; Kornberg et al., 1992; Lipfert et al., 1992; Miyamoto et al., 1995). Upon integrin engagement, FAK becomes phosphorylated on tyrosine-397, creating a high affinitybinding site for src and src family kinases (Schaller et al., 1994). The FAK/Src complex, in turn mediates phosphorylation of several associated focal adhesion proteins, in addition to phosphorylation of additional sites on FAK by src kinase (Calalb et al., 1995; Polte and Hanks, 1995; Schaller and Parsons, 1995; Calalb et al., 1996). Although several substrates of the FAK/src bipartite kinase complex have been recently identified as regulators of migration (Cary et al., 1998; Klemke et al., 1998; Petit et al., 2000), the mechanisms whereby FAK/src signaling pathways regulate migration are largely unknown.

Several studies have reported elevated expression and activity of FAK and src kinase in advanced progression stages of several types of human cancer including colon, thyroid, prostate and ovarian cancers (Talamonti et al., 1993; Owens et al., 1996; Tremblay et al., 1996; Mao et al., 1997; Judson et al., 1999). It was recently reported that overexpression of the dominantnegative mutant types of FAK and src kinase suppresses motility and invasiveness of human carcinoma cells (Huak et al., 2001; Sakamoto et al., 2001). Slack et al. (2001) also showed a correlation between alterations in FAK/src signaling pathway and increased migratory capacity of prostate cancer cells. The involvement of FAK and src in the regulation of motility and invasion was also revealed in breast cancer cells by the following results from several groups: (1) FAK expression level is strongly associated with invasion and metastasis of breast cancer (Weiner et al., 1993; Cance et al., 2000); (2) FAK can modulate an inhibitory effect of sphingosine 1-phosphate on motility of MDA-MB-231 breast cancer cells (Wang et al., 1999); (3) Src kinase is required for hepatocyte growth factor-induced motility of mouse mammary carcinoma cells (Rahimi et al., 1998). Therefore, it is likely that any signaling pathway leading to an increase in expression and activity of focal adhesion kinase and src kinase could promote motility of breast cancer cells. Although it is uncertain whether the CD99 type II expression correlates with a malignant progression of breast cancer, the data in this study suggest that the CD99 slice variant is one of the molecules which can activate focal adhesion kinase and src kinase by triggering its own signal transduction pathway for the induction of motility and invasiveness of human breast cancer cells.

\section{Acknowledgements}

This study was supported by a research fund from Korea Research Foundation (2000-015-DP0311).

\section{References}

Ambros IM, Ambros PF, Strehl S, Kovar H, Gadner H, SalzerKuntschik M. MIC2 is a specific marker for Ewing's sarcoma and peripheral primitive neuroectodermal tumors: evidence for a common histogenesis of Ewing's sarcoma and peripheral 
primitive neuroectodermal tumors from MIC2 expression and specific chromosome aberration. Cancer 1991;67:1886-93

Bernard G, Zoccola D, Deckert M, Breittmayer JP, Aussel C, Bernard A. The E2 molecule (CD99) specifically triggers homotypic aggregation of $\mathrm{CD} 4^{+} \mathrm{CD} 8^{+}$thymocytes. $\mathrm{J}$ Immunol 1995;154:26-32

Calalb MB, Polte TR, Hanks SK. Tyrosine phosphorylation of focal adhesion kinase at sites in the catalytic domain regulates kinase activity: a role for Src family kinases. Mol Cell Biol 1995;15:954-63

Calalb MB, Zhang X, Polte TR, Hanks SK. Focal adhesion kinase tyrosine-861 is a major site of phosphorylation by Src. Biochem Biophys Res Commun 1996;228:662-68

Cance WG, Harris JE, lacocca MV, Roche E, Yang X, Chang J, Simkins S, Xu L. Immunohistochemical analyses of focal adhesion kinase expression in benign and malignant human breast and colon tissues: correlation with preinvasive and invasive phenotypes. Clin Cancer Res 2000;6:2417-23

Cary LA, Han DC, Polte TR, Hanks SK, Guan JL. Identification of p130Cas as a mediator of focal adhesion kinase-promoted cell migration. J Cell Biol 1998;140:211-21

Choi EY, Park WS, Jung KC, Kim SH, Park SH. Engagement of CD99 induces up-regulation of TCR and MHC class I and II molecules on the surface of human thymocytes. J Immunol 1998;161:749-54

Guan JL, Shalloway D. Regulation of focal adhesionassociated protein tyrosine kinase by both cellular adhesion and oncogenic transformation. Nature 1992;358:690-92

Hahn J-H, Kim MK, Choi EY, Kim SH, Sohn HW, Ham DI, Chung DH, Kim TJ, Lee WJ, Park CK, Ree HJ, Park SH. CD99 (MIC2) regulates the LFA-1/ICAM-1-mediated adhesion of lymphocytes, and its gene encodes both positive and negative regulators of cellular adhesion. $\mathrm{J}$ Immunol 1997; 159:2250-58

Hahn M-J, Yoon SS, Sohn HW, Song HG, Park SH, Kim TJ. Differential activation of MAP kinase family members triggered by CD99 engagement. FEBS Lett 2000;470:350-54

Ha-Lee YM, Lee Y, Kim YK, Sohn J. Cross-linking of CD4 induces cytoskeletal association of CD4 and p56 cke . Exp Mol Med 2000;32:18-22

Hauck CR, Sieg DJ, Hsia DA, Loftus JC, Gaarde WA, Monia BP, Schlaepfer, DD. Inhibition of focal adhesion kinase expression or activity disrupts epidermal growth factorstimulated signaling promoting the migration of invasive human carcinoma cells. Cancer Res 2001;61:7079-90

Judson PL, He X, Cance WG, Van L. Overexpression of focal adhesion kinase, a protein tyrosine kinase, in ovarian carcinoma. Cancer 1999;86:1551-56

Kasinrerk W, Tokrasinwit N, Moonsom S, Stockinger H. CD99 monoclonal antibody induce homotypic adhesion of Jurkat cells through protein tyrosine kinase and protein kinase Cdependent pathway. Immunol Lett 2000;71:33-41

Kim E, Lee H-J, Hahn J-H, Park SH, Lee H. Expression of a spliced variant of CD99 membrane protein increases motility, matrix degradation, and invasiveness of human breast carcinoma cells. Proc Am Assoc Cancer Res 2000;41:231-32

Klemke RL, Leng J, Molander R, Brooks PC, Vuori K, Cheresh DA. CAS/Crk coupling serves as a "molecular switch" for induction of cell migration. J Cell Biol 1998; 140:961-72

Kornberg LJ, Earp HS, Parsons JT, Schaller MD, Juliano RL. Cell adhesion or integrin clustering increases phosphorylation of a focal adhesion-associated tyrosine kinase. J Biol Chem 1992;267:23439-42

Kovar H, Dworzak M, Strehl S, Schnell E, Ambros IM, Amros $\mathrm{PF}$, Gadner H. Overexpression of the pseudoautosomal gene MIC2 in Ewing's sarcoma and peripheral primitive neuroectodermal tumor. Oncogene 1990;5:1067-70

Lee $\mathrm{H}$, Hsu S, Winawer S, Friedman E. Signal transduction through extracellular signal-regulated kinase-like pp57 blocked in differentiated colon carcinoma cells having low levels of c-src kinase. J Biol Chem 1993;268:8181-87

Levy R, Dilley J, Fox RI, Warnk R. A human thymus-leukemia antigen defined by hybridoma monoclonal antibodies. Proc Natl Acad Sci USA 1979;76:6552-56

Lipfert L, Haimovich B, Schaller MD, Cobb BS, Parsons JT, Brugge JS. Integrin-dependent phosphorylation and activation of the protein tyrosine kinase pp125FAK in platelets. J Cell Biol 1992;119:905-12

Mao W, Irby R, Coppola D, Fu L, Wloch M, Turner J, Yu H, Garcia R, Jove R, Yeatman TJ. Activation of c-Src by receptor tyrosine kinases in human colon cancer cells with high metastatic potential. Oncogene 1997;15:3083-90

Miyamoto S, Teramoto H, Coso OA, Gutkind JS, Burbelo PD, Akiyama SK, Yamada KM. Integrin function: molecular hierarchies of cytoskeletal and signaling molecules. J Cell Biol 1995;131:791-805

Owens LV, Xu L, Dent GA, Yang X, Sturge GC, Craven RJ, Cance WG. Focal adhesion kinase as a marker of invasive potential in differentiated human thyroid cancer. Ann Surg Oncol 1996;3:100-05

Petit V, Boyer B, Lentz D, Turner CE, Thiery JP, Valles AM. Phosphorylation of tyrosine residues 31 and 118 on paxillin regulates cell migration through an association with CRK in NBT-II cells. J Cell Biol 2000;148:957-70

Polte TR, Hanks SK. Interaction between focal adhesion kinase and Crk-associated tyrosine kinase substrate p130Cas. Proc Natl Acad Sci USA 1995;92:10678-82

Rahimi N, Hung W, Tremblay E, Saulnier R, Elliott B. c-Src kinase activity is required for hepatocyte growth factorinduced motility and anchorage-independent growth of mammary carcinoma cells. J Biol Chem 1998;273:33714-21

Sakamoto M, Takamura M, Ino Y, Miura A, Genda T, Hirohashi $\mathrm{S}$. Involvement of $\mathrm{C}$-Src in carcinoma cell motility and metastasis. Jpn J Cancer Res 2001;92:941-46

Schaller MD, Hildebrand JD, Shannon JD, Fox JW, Vines RR, Parsons JT. Autophosphorylation of the focal adhesion kinase, 
pp125FAK, directs SH2-dependent binding of pp60src. Mol Cell Biol 1994;14:1680-88

Schaller MD, Parsons JT. pp125FAK-dependent tyrosine phosphorylation of paxillin creates a high-affinity binding site for Crk. Mol Cell Biol 1995;15:2635-45

Shin EY, Kim SY, Kim EG. c-Jun N-terminal kinase is involved in motility of endothelial cell. Exp Mol Med 2001;33:276-83

Slack JK, Adams RB, Rovin JD, Bissonette EA, Stoker CE, Parsons JT. Alterations in the focal adhesion kinase/Src signal transduction pathway correlate with increased migratory capacity of prostate carcinoma cells. Oncogene 2001;20:1152-63

Sohn HW, Shin YK, Lee I-S, Bae YM, Suh YH, Kim MK, Kim TJ, Jung KC, Park WS, Park C-S, Chung DH, Ahn K, Kim IS, Ko YH, Bang YJ, Kim CW, Park SH. CD99 regulates the transport of $\mathrm{MHC}$ class I molecules from the Golgi complex to the cell surface. J Immunol 2001;166:787-94

Talamonti MS, Roh MS, Curley SA, Gallick GE. Increase in activity and level of pp60c-src in progressive stages of human colorectal cancer. J Clin Invest 1993;91:53-60
Tremblay L, Hauck W, Aprikian AG, Begin LR, Chapdelaine A, Chevalier S. Focal adhesion kinase (pp125FAK) expression, activation and association with paxillin and p50CSK in human metastatic prostate carcinoma. Int J Cancer 1996;68:164-71

Waclavicek M, Majdic O, Stunlnig T, Berger M, SunderPlassmann R, Zlabinger GJ, Baumruker T, Stockl J, Ebner C, Knapp W, Pickl WF. CD99 engagement on human peripheral blood $T$ cells results in TCR/CD3-dependent cellular activation and allows for Th1-restricted cytokine production. J Immunol 1998;161:4671-78

Wang F, Nohara K, Olivera A, Thompson EW, Spiegel S. Involvement of focal adhesion kinase in inhibition of motility of human breast cancer cells by sphingosine 1-phosphate. Exp Cell Res 1999;247:17-28

Weiner TM, Liu ET, Craven RJ, Cance WG. Expression of focal adhesion kinase gene and invasive cancer. Lancet 1993;342:1024-25

Wingett D, Forcier K, Nielson CP. A role for CD99 in T cell activation. Cell Immunol 1999;193:17-23 